\title{
Simple Thinking Makes Chemistry Metabolic and Interesting - A Review Article
}

\author{
Arijit Das \\ Ph.D., MACS (Invited,USA), FICS, FISC, FIAFS (Ind) \\ Department of Chemistry, Ramthakur College, Agartala, Tripura West, Tripura, India
}

\begin{abstract}
First of all I give my love to all the students who reside in 'Chemistry Phobia zone'. In this short article I shall try to share my simple thinking that I achieved during my last 16 years of journey in the route of Chemical Education. Before starting my journey it was a big encounter for me to change the conventional methods and makes chemistry easier and interesting to such student who belongs to Chemistry Paranoia Zone. I believe that students are just like flowers and it is our duty to nourish them properly as a gardener. In my infinitely small area of knowledge, I just try to innovate fourteen (14) teaching methodologies by including thirty four (34) completely new formulae in the chemistry world which were followed by different eminent writers in their books since last 90-95 years namely Sir G.Wilkinson, Prof. F. Albert Cotton, Prof. I.L.Finar, Prof. R.T. Morrison, Prof. R.N. Boyd, Prof. Solomons and Prof. Fryhle, Prof. J.G. Smith etc..

Keywords: Hybridization, Bond-order, Acid radical, Bond-Distances, Spin Multiplicity, Aromatic and Anti aromatic compound, Magnetic Moment, Open chain olefinic system, cyclic olefinic system, $\pi$ and $\sigma$-bond, double and single bond, number of carbon and hydrogen atoms.
\end{abstract}

\section{Introduction}

The conventional methods ${ }^{1-11}$ for determination of Hybridization, bond order of mono and diatomic homo and hetero nuclear molecules or ions having total electrons (01-20) using M.O.T., bond-order of oxide based acid radicals, 'IUPAC nomenclature of spiro and bicyclo compounds, 'spin multiplicity value calculation', 'Aromatic and Anti-Aromatic behavior of Organic compunds', 'magnetic properties of homo and hetero nuclear diatomic molecules and ions, 'simultaneous equations as a tool in the spectrophotometric analysis of two non-interacting substances in a binary mixture, prediction of Magnetic Moment of homo and hetero nuclear mono and diatomic molecules or ions without MOT, calculation of the number of $\pi$-bonds, $\sigma$-bonds, single and double bonds in aliphatic unsaturated open chain and cyclic olefinic hydrocarbons and alkyne system etc. is time consuming. Keeping this in mind, I introduced some new innovative methods ${ }^{12-23}$ to make chemistry easier and interesting. Here, I have tried to discuss few of them shortly.

\section{Result And Discussion:}

New Innovative Teaching and Learning Methodologies

A. Hybridization state determination (for $s p, s p^{2}, s p^{3}, s p^{3} d, s p^{3} d^{2}, s p^{3} d^{3}$ hybridization) concept proposed by Linus Pauling in 1931-1932 :

We Know that, Hybridization is nothing but the mixing of orbital's in different ratio to form some newly synthesized orbitals called hybrid orbitals. The mixing pattern is as follows:

$\mathrm{s}+\mathrm{p}(1: 1)-\mathrm{sp}$ hybrid orbital $; \mathrm{s}+\mathrm{p}(1: 2)-\mathrm{sp}^{2}$ hybrid orbital $; \mathrm{s}+\mathrm{p}(1: 3)-\mathrm{sp}^{3}$ hybrid orbital

Formula for determination of hybridization state like $\mathrm{sp}, \mathrm{sp}^{2}, \mathrm{sp}^{3}$ followed the following method:

Power of the Hybridization state of the centre atom

$$
=(\text { Total no of } \sigma \text { bonds around each centre atom }-1)
$$

All single (-) bonds are $\sigma$ bond, in double bond $(=)$ there is one $\sigma$ and $1 \pi$, in triple bond there is one $\sigma$ and $2 \pi$. In addition to these each lone pair (i.e.no of electrons in the outermost orbit which should not take part in bond formation) and Co-ordinate bond can be treated as one $\sigma$ bond.

Eg. In $\mathrm{H}_{3} \mathrm{BO}_{3}-\mathrm{B}$ has $3 \sigma$ bonds (3BPs but no LPs) and oxygen has $4 \sigma$ bonds (2BPs \& 2LPs) so, in this case power of the hybridization state of $\mathrm{B}=3-1=2$ i.e. $\mathrm{B}$ is sp $\mathrm{sp}^{2}$ hybridized in $\mathrm{H}_{3} \mathrm{BO}_{3}$. on the other hand, power of the hybridization state of $\mathrm{O}=4-1=3$ i.e. hybridization state of $\mathrm{O}_{3}$ in $\mathrm{H}_{3} \mathrm{BO}_{3}$ is sp .

For determination of the hybridization state like $\mathrm{sp}^{3} \mathrm{~d}, \mathrm{sp}^{3} \mathrm{~d}^{2}, \mathrm{sp}^{3} \mathrm{~d}^{3}$ followed the following method:-

In case of $\mathrm{sp}^{3} \mathrm{~d}, \mathrm{sp}^{3} \mathrm{~d}^{2}$ and $\mathrm{sp}^{3} \mathrm{~d}^{3}$ hybridization state there is a common term $\mathrm{sp}^{3}$ for which 04 sigma bonds are responsible. So, in addition to 04 sigma bonds, for each additional sigma, added one d orbital gradually as follows:-

$5 \sigma$ bonds $=4 \sigma$ bonds +01 additional $\sigma$ bond $=\mathrm{sp}^{3} \mathrm{~d}$ hrbridization;

$6 \sigma$ bonds $=4 \sigma$ bonds +02 additional $\sigma$ bonds $=s^{3} d^{2}$ hrbridization;

$7 \sigma$ bonds $=4 \sigma$ bonds +03 additional $\sigma$ bonds $=s^{3} d^{3}$ hrbridization. 
Eg. $\mathrm{IF}_{4}^{+}$: I has 07 e-s in its outermost shell, so, in this case, subtract one e from 07 i.e. $07-1=06$. So, out of 06 electrons, 04 electrons form $04 \mathrm{I}-\mathrm{F}$ bonds i.e. 04 sigma bonds and there is one LP. So, altogether there is $05 \sigma$ bonds. So, $5 \sigma$ bonds $=04 \sigma$ bonds +01 additional $\sigma$ bond $=\mathrm{sp}^{3} \mathrm{~d}$ hrbridization.

B. For Bond Order of mono and diatomic homo and hetero nuclear molecules or ions having (1-20)e-s and oxide based acid radicals without M.O.T. proposed by Friedrich Hund and Robert Mulliken in 1933 :-

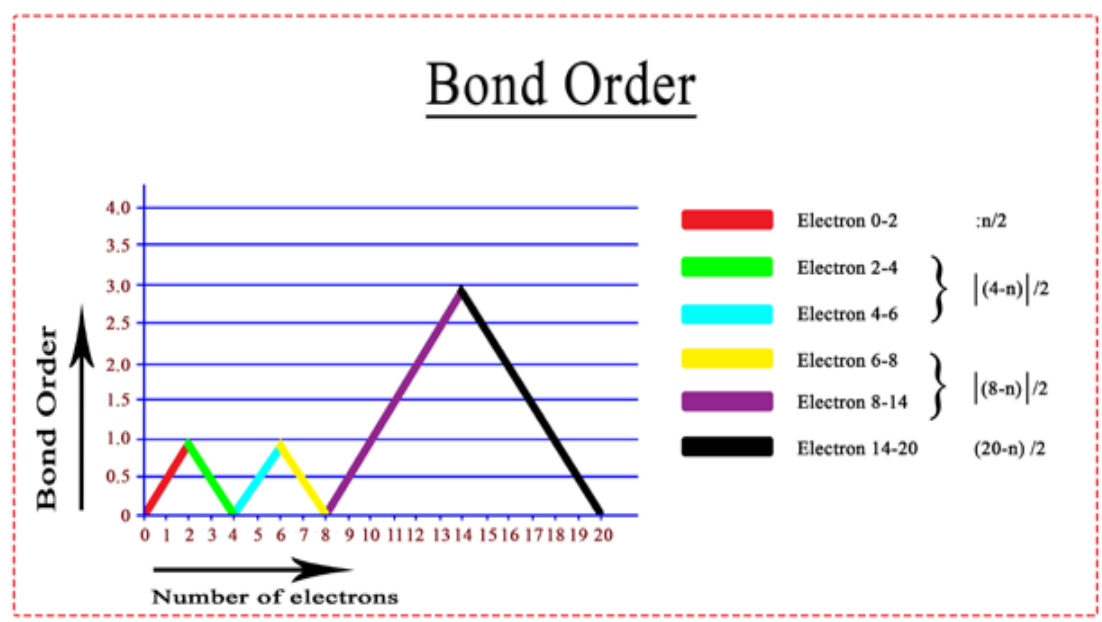

Fig:-1 (B.O. vs number of electrons)

The graphical representation presented in Fig. 1 shows that bond-order gradually increases to 01 in the range (0-02) electrons then it falls to zero in the range (02-04) electrons then it further rises to 01 for (04-06) electrons and once again falls to zero for (06-08) electrons then again rises to 3 in the range (08-14) electrons and then finally falls to zero for (14-20) electrons. For total no of electrons 2, 6 and 14, we use multiple formulae, because they fall in the overlapping region in which they intersect with each other.

First of all we classify the molecules or ions into four (04) types based on the total no of electrons.

i) Molecules and ions having total no of electrons within the range (0-2).

In such case Bond order $=\mathbf{n} / 2$; [Where $n=$ Total no of electrons]

Eg. $\mathrm{H}_{2}($ Total e $s=02)$, Therefore B.O. $=\mathrm{n} / 2=02 / 2=1$

ii) Molecules and ions having total no of electrons within the range (2-6).

In such case Bond order = I 4- n I / 2 ;

[Where $\mathrm{n}=$ Total no of electrons, 'I I' indicates Mod function i.e. the value of bond order is always positive]

Eg. $\mathrm{Li}_{2}{ }^{+}\left(5 \mathrm{e}^{-} \mathrm{s}\right)$ Therefore B.O. $=\mathrm{I} 4-5 \mathrm{I} / 2=1 / 2=0.5$.

iii)Molecules and ions having total no of electrons within the range (6-14).

In such case Bond order $=$ I 8-n I / 2

Eg: CO (Total e $\left.\mathrm{e}^{-\mathrm{s}}=06+08=14\right)$, Therefore B.O.= I 08-14 I / $2=3$

iv)Molecules and ions having total no of electrons within the range (14-20).

In such case Bond order $=(20-n) / 2$; [Where $n=$ Total no of electrons $]$

Eg. NO (Total e`s $=15$ ), Therefore B.O. $=20-15 / 2=2.5$

C. Bond order of oxide based Acid Radicals:

In case of Acid Radicals

B.O.=Valency of one of the peripheral atom + (Charge on Acid Radical / Total number of

Eg. peripheral atoms)

$\mathrm{ClO}_{4}{ }^{-}$; (Valency of one Peripheral atom i.e. Oxygen $=2$, Charge on acid radical $=-1$, Total Number of Peripheral atoms $=04)$, Therefore B.O. $=2+(-1 / 4)=(8-1) / 4=7 / 4=1.75$

$\mathrm{ClO}_{3}^{-}$; (Valency of one Peripheral atom i.e. Oxygen $=2$, Charge on acid radical $=-1$, Total Number of Peripheral atoms $=03)$, Therefore B.O. $=2+(-1 / 3)=(6-1) / 3=5 / 3=1.66$

$\mathrm{ClO}_{2}^{-}$; (Valency of one Peripheral atom i.e. Oxygen $=2$, Charge on acid radical $=-1$, Total Number of Peripheral atoms $=02)$, Therefore B.O. $=2+(-1 / 2)=(4-1) / 2=3 / 2=1.5$ 
$\mathrm{AsO}_{4}{ }^{3-}$; (Valency of one Peripheral atom i.e. Oxygen $=2$, Charge on acid radical $=-3$, Total Number of Peripheral atoms $=04)$, Therefore B.O. $=2+(-3 / 4)=(8-3) / 4=5 / 4=1.25$

$\mathrm{AsO}_{3}{ }^{3-}$; (Valency of one Peripheral atom i.e. Oxygen $=2$, Charge on acid radical $=-3$, Total Number of Peripheral atoms $=03)$, Therefore B.O. $=2+(-3 / 3)=1.0$

Correlation among / between Literature values of bond-distances of some oxide based acid radicals with their predicted bond order values:

Literature values of the $\mathrm{Cl}-\mathrm{O}$ average bond lengths in $\mathrm{ClO}_{4}{ }^{-}, \mathrm{ClO}_{3}{ }^{-}$and $\mathrm{ClO}_{2}{ }^{-}$; As-O bond lengths in $\mathrm{AsO}_{4}{ }^{3-}$ and $\mathrm{AsO}_{3}{ }^{3-}$ w.r.t. their Bond order suggest that with increasing bond-order $\mathrm{M}-\mathrm{O}$ bond length (Where $\mathrm{M}=\mathrm{Cl}, \mathrm{As}$ etc.) decreases which is tabulated below.

Table-1 (Correlation of some bond-distances with their predicted bond order values)

\begin{tabular}{|c|c|c|c|}
\hline Oxide Based Acid Radicals & Bond-Order Values & $\begin{array}{c}\text { Avg. M-O Bond-Distances } \\
\text { As per Literature }(\AA)\end{array}$ & 1.50 \\
\hline $\mathrm{ClO}_{4}^{-}$ & 1.75 & 1.57 & Remarks \\
\hline $\mathrm{ClO}_{3}{ }^{-}$ & 1.6 & 1.64 & Increasing Bond-Order \\
decreases Bond Length & 1.75 \\
\hline $\mathrm{ClO}_{2}{ }^{3-}$ & 1.5 & 1.77 \\
\hline $\mathrm{AsO}_{3}{ }^{3-}$ & 1.25 & 1.0 & \\
\hline
\end{tabular}

D. Magnetic Properties of homo and hetero nuclear diatomic molecules or ions without MOT:

The present study involves three new formulae by just manipulating the number of unpaired electrons (n) using mod function (based on Applied Mathematics) and by means of these $n$ values one can easily stumble the magnetic moment values in Bohr-Magneton using spin only formula $\mu_{\mathrm{s}}=\bigvee_{\mathrm{n}}(\mathrm{n}+2)$ B.M., where B.M. $=$ Bohr Magneton $=$ Unit of Magnetic Moment, $\mathrm{n}=$ number of unpaired electrons.

First of all we classify the molecules or ions depending on the total number of electrons present in them in the following three (03) sets.

Set-1: Molecules or ions having (1-3)es, (3-5)ess, (5-7)e`s, (7-10)ess, (13-16)ess

Set-2: Molecules or ions having (10-13)e $e^{-s}$ and (16-19)e $\mathrm{s}$

Set-3: Molecules or ions having 20 e's

Then for different set we have to use three different formulae to calculate the number of unpaired electrons and thus magnetic moment ( $\mu_{s}$ in B.M.) can be evaluated in the following way:

F-1(For Set-1) - for the determination of number of unpaired electrons (n) of molecules or ions having total number of electrons (1-3), (3-5), (5-7), (7-10) and(13-16)e's:

In this case, the number of unpaired electrons $n=[$ I (ND - total e-s) I ]

Here, $\mathrm{ND}=$ next digit i.e. digit next to minimum digit and 'I I' indicates Mod Function.

Eg:Molecules or ions having (1-3) $\mathrm{e}^{-} \mathrm{s}$, in this case $\mathrm{ND}=2$ because here minimum digit is 1 .

Therefore, for $\mathrm{He}_{2}{ }^{+}\left(3 \mathrm{e}^{-} \mathrm{s}\right)$, the total number of electrons will be $3, \mathrm{ND}=2$,

Hence, unpaired electron $\mathrm{n}=\mathrm{I}(\mathrm{ND}-$ total e-s) $\mathrm{I}=\mathrm{I}(2-3) \mathrm{I}=1$

Hence, Magnetic Moment $\mu_{\mathrm{s}}=\sqrt{\mathrm{n}}(\mathrm{n}+2) \mathrm{B} . \mathrm{M} .=\sqrt{ } 1(1+2) \mathrm{BM}=\sqrt{ } 3 \mathrm{BM}=1.73 \mathrm{BM}$

For the molecules or ions containing (3-5)e $\mathrm{e}^{-\mathrm{s}}$, (5-7) $\mathrm{e}^{-\mathrm{s}}$, (7-10)e $\mathrm{e}^{-\mathrm{s}}$, and (13-16) $\mathrm{e}^{-\mathrm{s}}$ the ND value will be 4, 6, 8 and 14 respectively.

Hence, the value of $n=$ [ I (4-total e-s) I ]; [ I (6- total e-s) I ] [ I (8- total e-s) I ] and [ I (14- total e-s) I ] respectively.

F-2(For Set-2) - for the determination of number of unpaired electrons (n) of molecules or ions having total number of electrons (10-13) and (16-19):

In this case, the number of unpaired electrons $n=[$ I (PD - total e`s) I ]

Here, $\mathrm{PD}=$ Penultimate electron digit (i.e. before last electron).

$\mathrm{Eg}$ : for $\mathrm{C}_{2}^{-}\left(13 \mathrm{e}^{-} \mathrm{s}\right)$, the total number of electrons will be $13, \mathrm{PD}=12$

Hence, unpaired electron $\mathrm{n}=\mathrm{I}(12-$ total e`s) $\mathrm{I}=\mathrm{I}(12-13) \mathrm{I}=1$

Hence, Magnetic Moment $\mu_{\mathrm{s}}=\sqrt{ } \mathrm{n}(\mathrm{n}+2) \mathrm{B} . \mathrm{M} .=\sqrt{ } 1(1+2) \mathrm{BM}=\sqrt{3} \mathrm{BM}=1.73 \mathrm{BM}$

For $\mathrm{F}_{2}\left(18 \mathrm{e}^{-} \mathrm{s}\right)$, the total number of electrons will be $18, \mathrm{PD}=18$

Hence, unpaired electron $\mathrm{n}=\mathrm{I}(18-$ total e`s) $\mathrm{I}=\mathrm{I}(18-18) \mathrm{I}=0$

Hence, Magnetic Moment $\mu_{\mathrm{s}}=\sqrt{ } \mathrm{n}(\mathrm{n}+2) \mathrm{B} . \mathrm{M} .=\sqrt{ } 0(0+2) \mathrm{BM}=0 \mathrm{BM}=$ Diamagnetic in nature.

F-3(For Set-3) - for the determination of number of unpaired electrons (n) of molecules or ions having total number of electrons 20:

In this case, the number of unpaired electrons $n=\left[\right.$ I $\left(20\right.$ - total $\left.\left.\mathrm{e}^{-} \mathrm{s}\right) \mathrm{I}\right]$

$\mathrm{Eg}$ : for $\mathrm{Ne}_{2}\left(20 \mathrm{e}^{-} \mathrm{s}\right)$, the total number of electrons will be 20 , 
Hence, unpaired electron $\mathrm{n}=\mathrm{I}(20$ - total e $\mathrm{e}) \mathrm{I}=\mathrm{I}(20-20) \mathrm{I}=0$

Hence, Magnetic Moment $\mu_{\mathrm{s}}=\sqrt{\mathrm{n}}(\mathrm{n}+2)$ B.M. $=\sqrt{ } 0(0+2) \mathrm{BM}=0 \mathrm{BM}=$ Diamagnetic in nature.

Table:-2(Magnetic moments of homo and hetero nuclear diatomic molecules or ions)

\begin{tabular}{|c|c|c|c|c|}
\hline Molecules or ions & $\begin{array}{l}\text { Total Number of } \\
\text { e's }\end{array}$ & $\begin{array}{c}\mathrm{n} \text { value } \\
\text { (no of unpaired } \\
\text { electrons) }\end{array}$ & $\begin{array}{l}\text { Magnetic moment }\left(\mu_{s}\right) \\
\text { in BM }\end{array}$ & Remarks \\
\hline $\mathrm{H}_{2}^{+}$ & 1 & 1 & 1.73 & Para magnetic \\
\hline $\mathrm{H}_{2}, \mathrm{He}_{2}^{2+}$ & 2 & 0 & 0 & Diamagnetic \\
\hline $\mathrm{H}_{2}^{-}, \mathrm{He}_{2}^{+}$ & 3 & 1 & 1.73 & Para magnetic \\
\hline $\mathrm{He}_{2}$ & 4 & 0 & 0 & Diamagnetic \\
\hline $\mathrm{Li}_{2}^{+}, \mathrm{He}_{2}^{-}$ & 5 & 1 & 1.73 & Para magnetic \\
\hline $\mathrm{Li}_{2}, \mathrm{He}_{2}{ }_{2}^{2-}, \mathrm{Be}_{2}{ }^{2+}$ & 6 & 0 & 0 & Diamagnetic \\
\hline $\mathrm{Be}_{2}^{+}, \mathrm{Li}_{2}^{-}$ & 7 & 1 & 1.73 & Para magnetic \\
\hline $\mathrm{Be}_{2}, \mathrm{Li}_{2}{ }^{2-}$ & 8 & 0 & 0 & Diamagnetic \\
\hline $\mathrm{Be}_{2}{ }^{-}, \mathrm{B}_{2}^{+}$ & 9 & 1 & 1.73 & Para magnetic \\
\hline $\mathrm{B}_{2}, \mathrm{Be}_{2}^{2-}, \mathrm{HF}$ & 10 & 2 & 2.82 & Para magnetic \\
\hline $\mathrm{B}_{2}^{-}, \mathrm{C}_{2}^{+}$ & 11 & 1 & 1.73 & Para magnetic \\
\hline $\mathrm{C}_{2}, \mathrm{~B}_{2}{ }^{2-}, \mathrm{N}_{2}{ }^{2+}, \mathrm{CN}^{+}$ & 12 & 0 & 0 & Diamagnetic \\
\hline $\mathrm{C}_{2}^{-}, \mathrm{N}_{2}^{+}$ & 13 & 1 & 1.73 & Para magnetic \\
\hline $\begin{array}{c}\mathrm{N}_{2}, \mathrm{CO}, \mathrm{NO}^{+}, \mathrm{C}_{2}{ }^{2-}, \mathrm{CN}^{-} \\
, \mathrm{O}_{2}{ }^{2+}\end{array}$ & 14 & 0 & 0 & Diamagnetic \\
\hline $\mathrm{N}_{2}^{-}, \mathrm{NO}, \mathrm{O}_{2}^{+}$ & 15 & 1 & 1.73 & Para magnetic \\
\hline $\mathrm{NO}^{-}, \mathrm{O}_{2}$ & 16 & 2 & 2.82 & Para magnetic \\
\hline $\mathrm{O}_{2}^{-}$ & 17 & 1 & 1.73 & Para magnetic \\
\hline $\mathrm{F}_{2}, \mathrm{O}_{2}{ }^{2-}, \mathrm{HCl}$ & 18 & 0 & 0 & Diamagnetic \\
\hline $\mathrm{F}_{2}^{-}$ & 19 & 1 & 1.73 & Para magnetic \\
\hline $\mathrm{Ne}_{2}$ & 20 & 0 & 0 & Diamagnetic \\
\hline
\end{tabular}

\section{E. Evaluation of Spin Multiplicity value, first discovered by Friedrich Hund in 1925. :}

The formula which is generally used for the prediction of spin multiplicity value is $[(2 S+1)$, where $S=$ $\Sigma \mathrm{s}=$ total spin quantum no] is time consuming. To keep the matter in mind a new innovative method has to be introduced for calculation of spin-multiplicity value in the easiest way by ignoring the calculation of total spin quantum number $(\mathrm{S}=\Sigma \mathrm{s})$.

First of all we should classify the species (atoms, molecules, ions or complexes) for which spin multiplicity should be evaluated into three types based on the nature of alignment of unpaired electrons present in them.

i) Species having unpaired electrons in upward alignment $(\uparrow)$ :

In this case, spin multiplicity $=(\mathbf{n}+1)$; where $n=$ number of unpaired electrons.

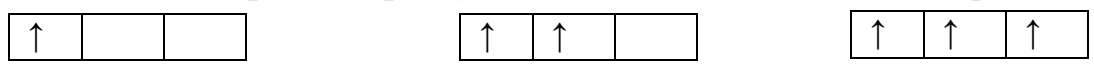

Spin multiplicity $=(n+1)=(1+1)=2($ spin state $=$ doublet $) ;(2+1)=3($ spin state $=$ triplet $)$ and $(3+1)=4($ spin state $=$ quartet $)$ respectively.

\section{\begin{tabular}{l|l|l|}
$\uparrow \downarrow$ & $\uparrow$ & $\uparrow$ \\
\hline
\end{tabular}$\quad$\begin{tabular}{|l|l|l|l|}
\hline$\downarrow$ & $\uparrow \downarrow$ & $\uparrow$ \\
\hline
\end{tabular}}

Spin multiplicity $=(\mathrm{n}+1)=(2+1)=3$ (in this case ignore paired electrons) $($ spin state $=$ triplet $)$ and $(1+1)=2$ $($ spin state $=$ doublet $)$

\begin{tabular}{|l|l|l|}
\hline$\uparrow \downarrow$ & $\uparrow \downarrow$ & $\uparrow \downarrow$ \\
\hline
\end{tabular}

Spin multiplicity $=(n+1)=(0+1)=1($ spin state $=$ singlet $)$

ii) Species having unpaired electrons in downward alignment $(\downarrow)$ :

In this case spin multiplicity $=(-n+1)$

Here (-ve) sign indicate downward arrow.

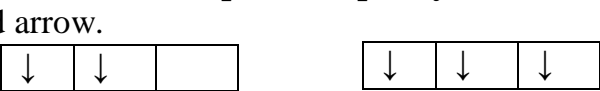

Spin multiplicity $=(-n+1)=(-1+1)=0 ;(-2+1)=-1$ and $(-3+1)=-2$ respectively. 


\section{\begin{tabular}{l|l|l|}
$\uparrow \downarrow$ & $\downarrow$ & $\downarrow$ \\
\hline
\end{tabular}}

\begin{tabular}{l|l|l|}
\hline$\uparrow$ & $\uparrow \downarrow$ & $\downarrow$ \\
\hline
\end{tabular}

Spin multiplicity $=(-n+1)=(-2+1)=-1$ (ignore paired electrons $)$ and $(-1+1)=0$ respectively.

iii) Species having unpaired electrons in both upward and downward alignment :

In this case spin multiplicity $=[(+n)+(-n)+1]$

where $n=$ number of unpaired electrons in each alignment. Here, $(+v e)$ sign and $(-v e)$ sign indicate upward and downward alignment respectively.

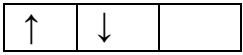

Here total no of unpaired electrons $=2$ in which one having upward direction $(+1)$ and other having downward mode $(-1)$.

Hence Spin multiplicity $=[(+n)+(-n)+1]=[(+1)+(-1)+1]=1($ spin state $=$ singlet $)$

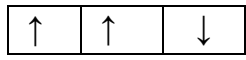

Here the total no of unpaired electrons $=3$ in which two unpaired electrons lie in upward $(+2)$ and one unpaired electrons lie in downward $(-1)$.

Hence Spin multiplicity $=[(+n)+(-n)+1]=[(+2)+(-1)+1]=2($ spin state $=$ doublet $)$

\begin{tabular}{|l|l|l|l|l|}
\hline$\uparrow$ & $\downarrow$ & $\uparrow$ & $\downarrow$ & $\uparrow$ \\
\hline
\end{tabular}

Here the total no of unpaired electrons $=5$ in which three unpaired electrons lie upward $(+3)$ and two unpaired electrons lie downward $(-2)$.

Hence Spin multiplicity $=[(+n)+(-n)+1]=[(+3)+(-2)+1]=2($ spin state $=$ doublet $)$

Table-3: spin multiplicity value and its corresponding spin state

\begin{tabular}{|c|c|}
\hline Spin multiplicity value & Spin state \\
\hline 1 & Singlet \\
\hline 2 & Doublet \\
\hline 3 & Triplet \\
\hline 4 & Quartet \\
\hline 5 & Quintet \\
\hline
\end{tabular}

F. Identification of Aromatic and Anti-Aromatic nature of Organic Compounds without Huckel's Rule of Aromaticity, devised by Huckel in 1931 :

The present study will be a new innovative method involving two formulae by just manipulating the no of $\pi$ bonds within the ring system and delocalized electron pair (excluding $\pi$ electron pair within the ring system) with one (01).

\section{i) Prediction of Aromatic behavior:}

In the first case, the compound must be cyclic, planar (i.e. all the carbon atoms having same state of hybridization) with even number of A value, where $[\mathbf{A}=\boldsymbol{\pi} \mathbf{b}+\mathbf{e} \mathbf{p}+\mathbf{1}$ (constant)], here $\pi \mathrm{b}=$ number of $\pi$ bonds with in the ring system and $e^{-p}=$ number of electron pair outside or adjacent to the ring system i.e. if the ring contains hetero atoms (atoms containing lone pair of electrons) which can undergo delocalization and each negative charge if present may be treated as one pair of electrons.

If the value of 'A', for a certain organic compound comes out as even number then this compound will be treated as aromatic compound.

\section{ii) Prediction of Anti-aromatic behavior:}

In the second case, the compound must be cyclic, planar (i.e. all the carbon atoms having same state of hybridization) with odd number of A value, where $[\mathbf{A}=\boldsymbol{\pi} \mathbf{b}+\mathbf{e} \mathbf{p}+\mathbf{1}$ (constant)], here $\pi \mathrm{b}=$ number of $\pi$ bonds with in the ring system and $e^{-p}=$ number of electron pair outside or adjacent to the ring system i.e. if the ring contains hetero atoms which can undergo delocalization and each negative charge if present, may be treated as one pair of electrons.

If the value of 'A', for a certain organic compound comes out as odd number then this compound will treat as anti-aromatic compound. 
Table -4.

(Aromatic and anti-aromatic nature of organic compounds by calculating A value)

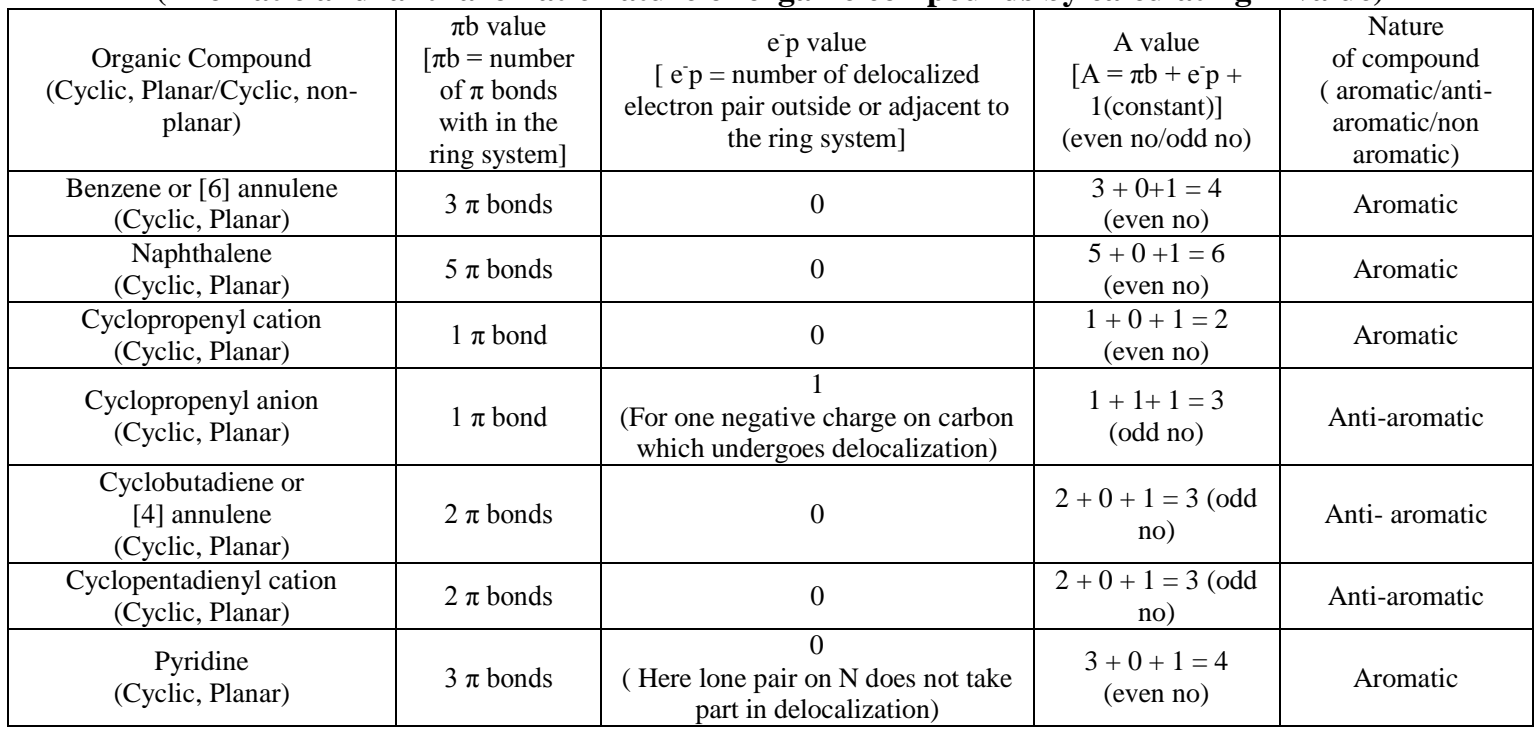

G. Rapid calculation of the number of $\pi$-bonds, $\sigma$-bonds, single and double bonds in aliphatic unsaturated open chain and cyclic olefinic hydrocarbons:

The molecular formula which defines a very large number of chemical structure, in this particular case, it is a herculean task to calculate the nature and number of bonds. Earlier Badertscher et al ${ }^{11}$ studied a novel formalism to characterize the degree of unsaturation of organic molecules ${ }^{1}$. But no such work has not been taken till now to calculate the number and types of bonds in open chain olefinic system having complex molecular formulae like $\mathrm{C}_{176} \mathrm{H}_{250}, \mathrm{C}_{2000} \mathrm{H}_{2000}$.

Keeping this in view, a rapid method has been proposed for the calculation of number of $\pi$-bonds, $\sigma$-bonds, single and double bonds with the help of following 06 (six) completely new formulae for certain aliphatic unsaturated open chain and cyclic olefinic hydrocarbons.

\section{For Open Chain Aliphatic Hydrocarbons:}

\section{Calculation of $\pi$-bonds and double bonds $(P)$ :}

In the first case, we have to count the number of carbon atoms $(\mathrm{X})$ and the number of hydrogen atoms $(\mathrm{Y})$ in a given unsaturated hydrocarbon containing double bonds.

The formula to calculate the number of $\pi$ bonds or double bonds for an aliphatic straight chain olefin is

$$
\mathbf{P}=[(2 \mathrm{X}-\mathrm{Y}) / 2]+\mathbf{1}
$$
bonds.

Where, $\mathrm{X}=$ number of carbon atoms; $\mathrm{Y}=$ number of hydrogen atoms and $\mathrm{P}=$ number of $\pi$ bonds/double

E.g.: In $\mathrm{C}_{176} \mathrm{H}_{250}, \mathrm{X}=176, \mathrm{Y}=250$, therefore $\mathrm{P}=(2 \times 176-250) / 2+1=51+1=52$ number of $\pi$ bonds or double bonds.

Calculation of $\sigma$-bonds $(S)$ :

In this case, first we have to count the number of carbon atoms (X) and the number of hydrogen atoms (Y) in the given unsaturated hydrocarbon containing double bonds.

The formula to calculate the number of $\sigma$ bonds for an aliphatic straight chain olefin is

$$
\mathbf{S}=[\mathbf{X}+\mathbf{Y}-\mathbf{1}]
$$
bonds).

Where, $\mathrm{X}=$ number of carbon atoms; $\mathrm{Y}=$ number of hydrogen atoms and $\mathrm{S}=$ number of sigma bonds $(\sigma-$

E.g.: In $\mathrm{C}_{176} \mathrm{H}_{250}, \mathrm{X}=176, \mathrm{Y}=250$, therefore $\mathrm{P}=176+250-1=425 \sigma$ bonds.

Calculation of Single bonds $(A)$ :

The total number of single bond for an aliphatic straight chain olefin is

$$
\mathrm{A}=[(3 \mathrm{Y} / 2)-2]
$$

where $\mathrm{A}=$ number of single bonds and $\mathrm{Y}$ is number of hydrogen atoms.

E.g.: In $\mathrm{C}_{176} \mathrm{H}_{250}, \mathrm{Y}=250$, therefore $\mathbf{A}=[(3 \times 250) / 2]=375-2=373$ single bonds. 


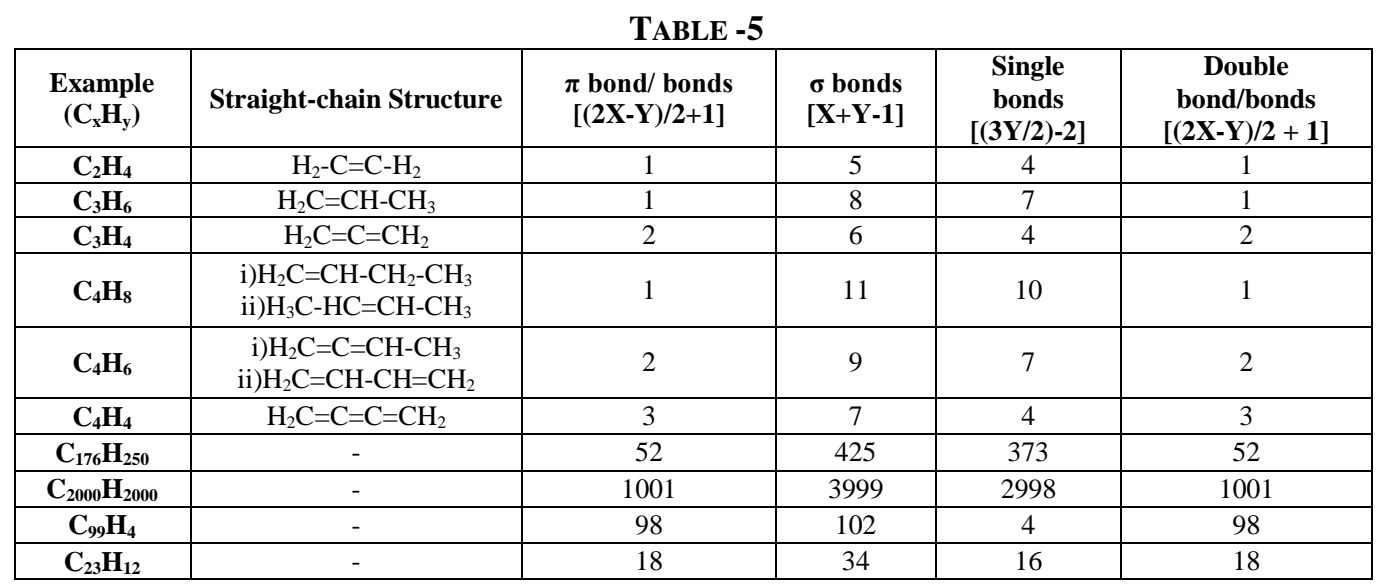

\section{For Cyclic aliphatic olefinic hydrocarbons:}

\section{Calculation of $\pi$-bonds and double bonds $\left(P_{c}\right)$ :}

In the first case, we have to count the number of carbon atoms $(\mathrm{X})$ and the number of hydrogen atoms $(\mathrm{Y})$ in the given unsaturated cyclic olefinic hydrocarbons.

The formula to calculate the number of $\pi$ bonds or double bonds for an aliphatic cyclic olefin is

$$
\mathbf{P}_{\mathrm{c}}=[(\mathbf{2 X}-\mathrm{Y}) / 2]
$$

Where, $\mathrm{X}=$ number of carbon atoms; $\mathrm{Y}=$ number of hydrogen atoms and $\mathrm{P}_{\mathrm{c}}=$ number of $\pi$ bonds or double bonds in the cyclic olefinic system.

E.g.: In cyclooctatetraene $\left(\mathrm{C}_{8} \mathrm{H}_{8}\right), X=Y=8$, therefore $\mathrm{P}_{c}=16-8 / 2=4$ number of $\pi$ bonds or double bonds.

\section{Calculation of $\sigma$-bonds $\left(S_{c}\right)$ :}

In the first case, we have to count the number of carbon atoms $(\mathrm{X})$ and the number of hydrogen atoms $(\mathrm{Y})$ in the given unsaturated cyclic olefinic hydrocarbons.

The formula to calculate the number of $\sigma$ bonds for an aliphatic cyclic olefin is

$$
\mathbf{S}_{\mathrm{c}}=[\mathbf{X}+\mathbf{Y}]
$$

Where, $\mathrm{X}=$ number of carbon atoms; $\mathrm{Y}=$ number of hydrogen atoms and $\mathrm{S}_{\mathrm{c}}=$ number of sigma bonds $(\sigma-$ bonds) in cyclic olefinic system.

Eg: In cyclooctatetraene $\left(\mathrm{C}_{8} \mathrm{H}_{8}\right), \mathrm{X}=\mathrm{Y}=8$, therefore $\mathrm{S}_{\mathrm{c}}=8+8=16$ number of $\sigma$ bonds.

Calculation of Single bonds $\left(A_{c}\right)$ :

The total number of single bonds in aliphatic cyclic olefin can be calculated by using the formula $\mathbf{A}_{\mathbf{c}}=$ [3Y/2] where $A_{c}=$ number of single bonds and $y$ is number of hydrogen atoms in aliphatic cyclic olefin.

E.g.: In cyclooctatetraene $\left(\mathrm{C}_{8} \mathrm{H}_{8}\right), Y=8$, therefore $A_{c}=24 / 2=12$ number of single bonds.

\begin{tabular}{|c|c|c|c|c|c|}
\hline $\begin{array}{c}\text { Example } \\
\left(\mathrm{C}_{\mathrm{x}} \mathrm{H}_{\mathrm{y}}\right)\end{array}$ & Cycloalkene & $\begin{array}{c}\pi \text { bond } / \text { bonds }\left(P_{c}\right) \\
= \\
{[(2 X-Y) / 2]}\end{array}$ & $\begin{array}{c}\sigma \text { bonds }\left(\mathbf{S}_{\mathbf{c}}\right) \\
{[\mathrm{X}+\mathrm{Y}]}\end{array}$ & $\begin{array}{c}\text { Single bonds } \\
\left(\mathbf{A}_{\mathrm{c}}\right) \\
{[(3 \mathrm{Y} / 2)]} \\
\end{array}$ & $\begin{array}{c}\text { Double } \\
\text { bond/bonds } \\
{[(2 \mathrm{X}-\mathrm{Y}) / 2]}\end{array}$ \\
\hline $\mathrm{C}_{3} \mathrm{H}_{4}$ & Cyclopropene & 1 & 7 & 6 & 1 \\
\hline $\mathrm{C}_{4} \mathrm{H}_{4}$ & Cyclobutadiene & 2 & 8 & 6 & 2 \\
\hline $\mathrm{C}_{5} \mathrm{H}_{6}$ & Cyclopentadiene & 2 & 11 & 9 & 2 \\
\hline $\mathrm{C}_{6} \mathrm{H}_{8}$ & Cyclohexadiene & 2 & 14 & 12 & 2 \\
\hline $\mathrm{C}_{7} \mathrm{H}_{8}$ & Cycloheptatriene & 3 & 15 & 12 & 3 \\
\hline $\mathrm{C}_{8} \mathrm{H}_{8}$ & Cyclooctatetraene & 4 & 16 & 12 & 4 \\
\hline
\end{tabular}

TABLE -6

\section{Conclusions:}

It is expected that these innovative methods would go a long way to help to the students of chemistry of Undergraduate, Senior Undergraduate and Post-Graduate level who would choose the subject as their career. Experiment in vitro on 100 students showed that by using these new innovative methods students can save up to 30-40 mins time in the examination hall. On the basis of this, I can strongly recommend to use these new metabolic interesting methods. 


\section{Acknowledgement:}

I would be grateful subsequently to Prof. G.N.Mukherjee(Retd.), Dept. of Chemistry, Calcutta University, Prof. R. N. Mukherjee, Director, IISER, Kolkata, Prof. P. K. Chattaraj, Convenor, centre for Theoretical studies, Deptt. of Chemistry, IIT Kharagpur, India,; Prof. Samar Kumar Das, School of Chemistry, University of Hyderabad, Prof. Partha Sarathi Mukherjee, Dept. of Chemistry, Indian Institute of Science, Bangalore, Prof. V. Jagannadam (Retd-), Dept. of Chemistry, Osmania University and Editor-in-Chief, World Journal of Chemical Education, SEP, USA, Prof. A. T. Khan, Head, Deptt. of Chemistry, IIT Patna, Dr. Satish Nimse, Dept. of Chemistry, Hyllym University, South Korea, Prof. A.K.Das, Ex Vice-Chancellor of Kalyani University, Prof. Nilashis Nandi, Dept. of Chemistry, Kalyani University, W.B., India, Prof. Md. Ali, Deptt. of Chemistry, Jadavpur University, Prof. R. A. Lal, Head, Dept. of Chemistry, NEHU, Shillong, Prof.M.K.Singh and Prof.R.K.Nath(Head), Deptt. of Chemistry, Tripura Central University for their appreciation and recognition in this regard.

Further, I would be grateful to Dr. S. Rakshit, Principal, Govt. Degree College, Dharmanagar, Tripura(N), Tripura, India, for giving him this opportunity to carry out the research work when he was at Govt. Degree College, Dharmanagar, North Tripura.

I would also be grateful to the Honble Chief Minister of the State, Mr. Manik Sarkar and Honble ExHigher Education Minister, Mr. Anil Sarkar for their felicitation with 'Certificate of Honour' on behalf of the state and Mr. Sekhar Datta, Chairman, tripurainfo.com and Senior Correspondent, 'The Telegraph' newspaper, Mr. Goutam Das, Editor, 'Daily Desher Katha' news Paper and Mr.Jayanta Debnath, MD, Tripurainfo.com for their valuable sustaining mentality in this regard.

Finally, I give my cordial thanks to the Director and Assistant Director of the prestigious American Chemical Society, USA, for sending me their invitation along with nomination to join the impressive ACS network.

\section{References:}

[1]. Lee.J.D.(2009 $5^{\text {th }}$ ed.), Concise Inorg. Chem, ; Wiley India and Oxford, 944 and 109-112.

[2]. Douglas.B.(2007 $3^{\text {rd }}$ ed.), Mcdaniel. D. and Alexander.J., Concepts and Models of Inorg. Chem.,; Wiley India, 157 and 38

[3]. Cotton.F.A.,Wilkinson.G.and Gaus.P.L.(2007 3 ${ }^{\text {rd }}$ ed.),Basic Inorg.Chem.,;Wiley India, 107, 523 \& 111.

[4]. Mahan. B.M. and Meyers.R.J. (1998 $4^{\text {th }}$ ed.),International Student Edition University Chemistry,599-603,

[5]. Dutta R.L., Inorganic Chem.(2009 $6^{\text {th }}$ ed.P1), 146-147.

[6]. Finar I.L, Organic Chemistry, Vol-1, (2004 $6^{\text {th }}$ ed. $), 1,532,577-580$, Pearson.

[7]. Morrison R.T. and Boyd R.N., $7^{\text {th }}$ ed., Organic Chemistry, 208, Pearson.

[8]. Solomons T.W.Graham and Fryhle C.B. (2009 \& $201210^{\text {th }}$ ed.), Organic Chemistry, 150, 632- 639, Wiley India.

[9]. Madan R.L.,Chem.(2011 $1^{\text {st }}$ ed.), p88.

[10]. Smith J.G. (2008 $2^{\text {nd }}$ ed.), Organic chemistry, 616-619.

[11]. Martin Badertscher, Kaspar Bischofberger, Morton E. Munk, and Erno Pretsch, 'A Novel Formalism To Characterize the Degree of Unsaturation of Organic Molecules'(2001), J. Chem.Inf. Comput. Sci. 41, 889-893.

[12]. Das Arijit (2013), 'New Innovative methods for prediction of Bond order of mono and diatomic molecules,ions and also acid radicals in a very short time', Ind. J. of Applied Research, 03(07), 114, ISSN-2249-555X.

[13]. Das Arijit (2013), 'New Innovative Methods for Prediction of Hybridization State in a Very Short Time',Ind. J. of Applied Research, 03(07), 594, ISSN-2249-555X.

[14]. Das Arijit (2013), 'New Innovative Methods for IUPAC Nomenclature of Bicyclo and Spiro Compounds in Organic Chemistry', Ind. J. of Applied Research, 03 (07), 596, ISSN-2249-555X.

[15]. Das Arijit (2013), 'New Innovative Methods for Determination of Spin Multiplicity, Spin State and Magnetic Properties of Diatomic Hetero Nuclear Molecules or Ions in a Very Short Interval of Time', Ind. J .of Applied Research,03(08), 67, ISSN2249-555X.

[16]. Das Arijit (2013), 'New Innovative methods for prediction Bond order of mono and diatomic molecules or ions having total number of (1-20)e's in a very short time', Ind. J. of Applied Research,03(09), 63, ISSN-2249-555X.

[17]. Das Arijit (2013), Adhikari Suman, Paul Bijaya, Sanjeev R. and Jagannadham V., 'A rapid and innovative method for the identification of aromatic and anti-aromatic nature of organic compounds', World Journal of Chemical Education, SEP, USA, $01(01), 6$.

[18]. Das Arijit (2013), 'A rapid and innovative method for the easy prediction of Magnetic behavior of homo and hetero nuclear mono and diatomic molecules or ions without MOT', Ind. J of Applied Research,03(10), 1, ISSN-2249-555X.

[19]. Sanjeev R, Jagannadham V., Ravi R., Veda R. Vrath and Das Arijit (2013), 'Simultaneous Equations as a Tool in the Spectrophotometric Analysis of Two Non-interacting Substances in a Binary Mixture: Senior Undergraduate Physical and Physical-Organic Chemistry Laboratory Experiment', Journal of Laboratory Chemical Education, SAP, USA, 1(4), 59, DOI:10.5923/j.jlce.20130104.01.

[20]. Das Arijit (2013), 'New Methods for Prediction of Bond Order of Mono and Diatomic Homo and Hetero Nuclear Molecules or Ions Having (1-20)e`s and Oxide Based Acid Radicals Without MOT - a Rapid Innovative Approach', Ind. J. of Applied Research, 03(11), 41, 2013, ISSN-2249-555X.

[21]. Das Arijit (2013), Pal Debapriya, Paul Bijaya, Sanjeev R. and Jagannadham V., 'Rapid calculation of the number of $\pi$-bonds, $\sigma$ bonds, single and double bonds in aliphatic unsaturated open chain and cyclic olefinic hydrocarbons', J. Ind. Chem. Soc. (in Press).

[22]. Das Arijit (2013), Pal Debapriya, Adhikari Suman, Paul Bijaya, Sanjeev R. and Jagannadham V.,'Rapid calculation of the number of $\pi$-bonds, $\sigma$-bonds, single and triple bonds in aliphatic Unsaturated open chain and cycloalkynes', World Journal of Chemical Education, SEP, USA (in press).

[23]. Das Arijit (2013), 'New Methods for the prediction of Magnetic Moment of homo and hetero nuclear mono and diatomic molecules or ions without MOT - A Rapid Innovative Approach', Int. J. of Adv. Res., 1, 1(10), USA. 